\title{
In vitro antioxidant effects of different extracts obtained from the leaves and seeds of Allium ampeloprasum subsp. persicum
}

\author{
Saba Feghhi-Najafabadi ${ }^{1}{ }^{\circledR}$, Leila Safaeian ${ }^{2 *}$, Behzad Zolfaghari ${ }^{3}$ \\ ${ }^{1}$ Student Research Committee, School of Pharmacy and Pharmaceutical Sciences, Isfahan University of Medical Sciences, Isfahan, Iran \\ ${ }^{2}$ Department of Pharmacology and Toxicology, Isfahan Pharmaceutical Sciences Research Center, School of Pharmacy and Pharmaceutical Sciences, \\ Isfahan University of Medical Sciences, Isfahan, Iran \\ ${ }^{3}$ Department of Pharmacognosy, School of Pharmacy and Pharmaceutical Sciences, Isfahan University of Medical Sciences, Isfahan, Iran
}

\section{A R T I C L E I N F O}

Article Type:

Short Communication

Article History:

Received: 10 March 2019

Accepted: 6 April 2019

Keywords:

Allium ampeloprasum

Antioxidant

DPPH

FRAP

$\mathrm{H} 2 \mathrm{O} 2$

\begin{abstract}
A B S T R A C T
Introduction: This study evaluated antioxidant effects of hexane, chloroform, chloroformmethanol, aqueous and butanol extracts of leaves and seeds of Allium ampeloprasum subsp. persicum.

Methods: Various extracts were evaluated for total phenolic content, ferric reducing antioxidant power (FRAP), 1,1-diphenyl-2-picrylhydrazyl (DPPH) and $\mathrm{H}_{2} \mathrm{O}_{2}$ scavenging activities.

Results: Total phenolic content varied from 2.46 to $8.12 \mathrm{mg}$ gallic acid equivalents (GAE) per gram for various extracts with the highest level for butanol leave extract. Butanol leave extract showed the lowest $\mathrm{IC}_{50}$ of DPPH scavenging. FRAP assay showed stronger antioxidant capacity for leaves than seeds' extracts and butanol extract was comparable to ascorbic acid at the concentration $50 \mu \mathrm{g} / \mathrm{mL}$. In $\mathrm{H}_{2} \mathrm{O}_{2}$ scavenging activity assay, butanol and chloroform-methanol leave extracts showed the least $\mathrm{IC}_{50}$ value.

Conclusion: Our results revealed moderately low amount of phenolic compounds and weak DPPH scavenging activity for all extracts of A. ampeloprasum subsp. persicum. However, leaves extracts showed good total antioxidant capacity and $\mathrm{H}_{2} \mathrm{O}_{2}$ scavenging activity.
\end{abstract}

Implication for health policy/practice/research/medical education:

The results of this study revealed better antioxidant activity for leaves extracts of A. ampeloprasum subsp.persicum than its seeds extracts through ferric reducing and scavenging of hydrogen peroxide. Therefore the leaves may be considered as the valuable plant part for medicinal and nutritional applications.

Please cite this paper as: Feghhi-Najafabadi S, Safaeian L, Zolfaghari B. In vitro antioxidant effects of different extracts obtained from the leaves and seeds of Allium ampeloprasum subsp. persicum. J Herbmed Pharmacol. 2019;8(3):256-260. doi: 10.15171/ jhp.2019.37.

\section{Introduction}

Oxidative stress has an important role in the pathogenesis of various diseases such as cancer, diabetes, aging, hypertension, atherosclerosis and neurodegenerative disorders (1). Antioxidants are substances which are able to prevent and protect against diseases related to oxidative stress through preventing the free radical formation, scavenging and neutralizing reactive oxygen species, and inhibiting oxidative reactions (2). Therefore, widespread interest has been recently concerned on the evaluation of antioxidant plants and phytochemicals for reducing the risk of various diseases and improving the quality of life $(3,4)$. Allium with around 800 species is an important genus of Amaryllidaceae family which widely spread in the northern hemisphere. The members of Allium genus are rich in various bioactive constituents including flavonoids, sulphuric compounds and saponins with a variety of biological activities including antimicrobial, antihypertensive, antihyperlipidemic, antidiabetic, antiatherosclerotic and anticarcinogenic effects (5). Allium ampeloprasum subsp. persicum is an endemic Iranian plant which is known as Persian Leek and widely cultivated all over the country (6). This edible vegetable is used as food or traditional herbal medicine. It has been used for the treatment of headache, hemoptysis, asthma, obesity, constipation, hemorrhoids and goat. It is also reported as an aphrodisiac, emmenagogue and diuretic agent in folk medicine (6). The seeds of A. ampeloprasum subsp. persicum have also been traditionally used as an appetizer and aphrodisiac, and for the treatment of neuralgia, vitiligo, 
chronic diarrhea, freckle and hemorrhoids (7). Since there is limited information about the antioxidant activities of different polarity extracts of leaves and seeds of this subspecies, the present study was aimed to investigate the antioxidant properties of hexane, chloroform, chloroformmethanol, aqueous and butanol extracts obtained from the leaves and seeds of $A$. ampeloprasum subsp. persicum in vitro.

\section{Materials and Methods}

Chemicals

The commercial kits for assessment of 1,1-diphenyl-2picrylhydrazyl (DPPH) radical scavenging, ferric reducing antioxidant power (FRAP) and hydrogen peroxide $\left(\mathrm{H}_{2} \mathrm{O}_{2}\right)$ scavenging activity were purchased from Hakiman Shargh Research Co. (Isfahan, Iran).

Plant material and preparation of extracts

The leaves and seeds of $A$. ampeloprasum subsp. persicum were purchased from a local market in Isfahan in August 2017. After identification of the plant, a voucher specimen (No. 2751) was deposited at the Herbarium of the School of Pharmacy and Pharmaceutical Sciences, Isfahan, Iran. Hexane, chloroform, chloroform-methanol, butanol and aqueous extracts were evaluated in this study. For preparation of each extract, the seeds or air-dried leaves were finely powdered and respectively extracted with hexane, chloroform, chloroform-methanol (9:1) or methanol using maceration method for 24 hours at room temperature. Methanol fraction was suspended in water for making aqueous extract and then extracted with butanol. After filtration and concentration under vacuum by rotary evaporator, each extract was freeze-dried and kept in the refrigerator till used for the assays.

Total phenolic assay

Total phenolic content of various extracts of leaves and seeds of $A$. ampeloprasum subsp. persicum was measured using Folin-Ciocalteu reagent (8). Briefly, the diluted reagent and $\mathrm{Na}_{2} \mathrm{Co}_{3}$ solution (20\%) were mixed with plant samples. Then, UV absorbance was detected at $765 \mathrm{~nm}$ using a UV-visible spectrophotometer. Total phenolics were estimated using a standard curve obtained from different concentrations of gallic acid. The total phenolic content was presented as milligram of gallic acid equivalents (GAE) per gram of dried plant extract.

DPPH radical scavenging activity assay

The scavenging effect of different extracts on $\mathrm{DPPH}$ free radical was evaluated based on previous studies (9). Briefly, methanol solution of DPPH was added to different concentrations of plant extracts $(10-1000 \mu \mathrm{g} / \mathrm{mL})$. The mixture was gently homogenized and after 30 minutes incubation in dark condition at room temperature, the absorbance was read at $517 \mathrm{~nm}$ using a microplate reader/spectrophotometer. The ability of plant extracts for scavenging DPPH was estimated using the formula $\left[\left(\mathrm{A}_{0}-\mathrm{A}_{1}\right) / \mathrm{A}_{0}\right] \times 100$, where $A_{0}$ is the absorbance of the control, and $A_{1}$ is the absorbance of the sample. Ascorbic acid was used as the standard reference. The half maximal inhibitory concentration $\left(\mathrm{IC}_{50}\right)$ values were calculated using their calibration curve.

Ferric reducing antioxidant power assay

The total antioxidant capacity of different plant extracts was evaluated by FRAP method. In this colorimetric assay, the reduction of ferric-tripyridyltriazine complex to ferrous form is expressed as antioxidant capacity. Briefly, the FRAP reagent was added to different concentrations of plant extracts $(10-1000 \mu \mathrm{g} / \mathrm{mL})$. Absorbance was read at $570 \mathrm{~nm}$ using a microplate reader/spectrophotometer. The FRAP value of samples was calculated using a standard curve of $\mathrm{FeSO}_{4} \times 7 \mathrm{H}_{2} \mathrm{O}$ and expressed as micromole of FeII equivalents per liter (10).

Hydrogen peroxide scavenging activity assay

The ability of different plant extracts to scavenge $\mathrm{H}_{2} \mathrm{O}_{2}$ was measured based on the ferrous ion oxidation by xylenol orange reagent (FOX1) Method. A solution of $\mathrm{H}_{2} \mathrm{O}_{2}(10$ $\mu \mathrm{L}, 2 \mathrm{mM}$ ) was mixed with $10 \mu \mathrm{L}$ of plant extracts (10-1000 $\mu \mathrm{g} / \mathrm{mL})$. Then, FOX1 reagent was added $(190 \mu \mathrm{L})$ and the absorbance of solution was measured at $540 \mathrm{~nm}$ using a microplate reader/spectrophotometer. The percentage of $\mathrm{H}_{2} \mathrm{O}_{2}$ scavenging was estimated using the formula [ $\left(\mathrm{A}_{0}\right.$ $\left.\left.\mathrm{A}_{1}\right) / \mathrm{A}_{0}\right] \times 100$, where $A_{0}$ is the absorbance of the control, and $A_{1}$ is the absorbance of the sample. $\mathrm{IC}_{50}$ values were calculated for plant and standard samples (11).

\section{Statistical analysis}

Data were expressed as mean \pm standard error of mean (SEM). For statistically evaluation, a one-way analysis of variance (ANOVA) followed by Tukey post hoc test was used (SPSS software version 16.0). $P$ values $<0.05$ were considered as significant.

\section{Results}

Total phenolic assay

For both seeds and leaves samples, butanol extract showed the highest and hexane extract showed the lowest level of phenolics and the total phenolic content in the leaves extract was higher than that of the seeds (Table 1).

$\mathrm{DPPH}$ radical scavenging activity assay

$\mathrm{IC}_{50}$ of ascorbic acid was $32 \mu \mathrm{g} / \mathrm{mL}$. DPPH scavenging activity was in the following order for various seeds extracts: chloroform-methanol $>$ chloroform $>$ butanol $>$ hexane $>$ aqueous extract, and for leaves extracts: butanol $>$ aqueous $>$ chloroform-methanol $>$ hexane $>$ chloroform extract (Table 1). 
Table 1. Total polyphenolic content as $\mathrm{mg}$ gallic acid equivalents (GAE)/g and half maximal inhibitory concentration (IC ${ }_{50}$ ) for 1,1-diphenyl-2-picrylhydrazyl (DPPH) scavenging activity of various extracts obtained from seeds and leaves of $A$. ampeloprasum subsp. persicum

\begin{tabular}{lllll}
\hline & \multicolumn{2}{l}{ Total polyphenolic content $(\mathrm{mg} \mathrm{GAE} / \mathrm{g})$} & \multicolumn{2}{l}{ DPPH scavenging activity $\left(\right.$ IC $\left.{ }_{50^{\prime}} \mu \mathrm{\mu g} / \mathrm{mL}\right)$} \\
\cline { 2 - 4 } Extract & Seeds & Leaves & Seeds & Leaves \\
\hline Butanol & $5.33 \pm 0.38^{\mathrm{a}}$ & $8.12 \pm 0.41^{\mathrm{a}}$ & $668^{\mathrm{a}}$ & $315^{\mathrm{a}}$ \\
Aqueous & $4.81 \pm 0.42^{\mathrm{a}}$ & $7.34 \pm 0.35^{\mathrm{a}}$ & $792^{\mathrm{a}}$ & $413^{\mathrm{b}}$ \\
Chloroform-methanol & $5.15 \pm 0.52^{\mathrm{a}}$ & $7.45 \pm 0.51^{\mathrm{a}}$ & $457^{\mathrm{b}}$ & $539^{\mathrm{b}}$ \\
Chloroform & $3.86 \pm 0.38^{\mathrm{b}}$ & $3.23 \pm 0.64^{\mathrm{b}}$ & $556^{\mathrm{c}}$ & $585^{\mathrm{c}}$ \\
Hexane & $2.95 \pm 0.28^{\mathrm{c}}$ & $2.46 \pm 0.55^{\mathrm{c}}$ & $720^{\mathrm{a}}$ & $554^{\mathrm{c}}$ \\
\hline
\end{tabular}

Values in each column with different superscripts are significantly different $(P<0.05)$.

Ferric reducing antioxidant power assay

The results indicated an increasing trend in total antioxidant capacity with increasing the extracts concentrations (Figure 1). There was a significant difference in FRAP value between different seeds extracts and ascorbic acid. The antioxidant activity of seeds extracts was in the following order at the concentration $100 \mu \mathrm{g} / \mathrm{mL}$ : chloroform-methanol $>$ hexane $>$ chloroform $=$ butanol $>$ aqueous extract. For the leaves extracts, the results showed stronger antioxidant capacity than the seeds' extracts and the butanol extract was comparable to ascorbic acid at the concentration $50 \mu \mathrm{g} / \mathrm{mL}$. The FRAP values were in the following order for leaves extracs: butanol $>$ chloroformmethanol > aqueous > hexane $>$ chloroform extract (Figure 2).

Hydrogen peroxide scavenging activity assay

There was increasing trend in $\mathrm{H}_{2} \mathrm{O}_{2}$ scavenging activity with increase in the sample concentration. $\mathrm{IC}_{50}$ value of ascorbic acid was $41 \mu \mathrm{g} / \mathrm{mL}$. The scavenging activity of seeds extract with $\mathrm{H}_{2} \mathrm{O}_{2}$ was in the following order: chloroform-methanol $=$ chloroform $\left(\mathrm{IC}_{50}=235 \mu \mathrm{g} / \mathrm{mL}\right)$ $>$ butanol $\left(\mathrm{IC}_{50}=471 \mu \mathrm{g} / \mathrm{mL}\right)>$ hexane $=$ aqueous extract $\left(\mathrm{IC}_{50}=937 \mu \mathrm{g} / \mathrm{mL}\right.$ ) (Figure 3). For the leaves extracts, the results were in the following order: butanol $\left(\mathrm{IC}_{50}=100\right.$ $\mu \mathrm{g} / \mathrm{mL})>$ chloroform-methanol $\left(\mathrm{IC}_{50}=145 \mu \mathrm{g} / \mathrm{mL}\right)>$ aqueous $\left(\mathrm{IC}_{50}=227 \mu \mathrm{g} / \mathrm{mL}\right)>$ hexane $\left(\mathrm{IC}_{50}=687 \mu \mathrm{g} / \mathrm{mL}\right)>$ chloroform extract $\left(\mathrm{IC}_{50}=810 \mu \mathrm{g} / \mathrm{mL}\right.$ ) (Figure 4 ).

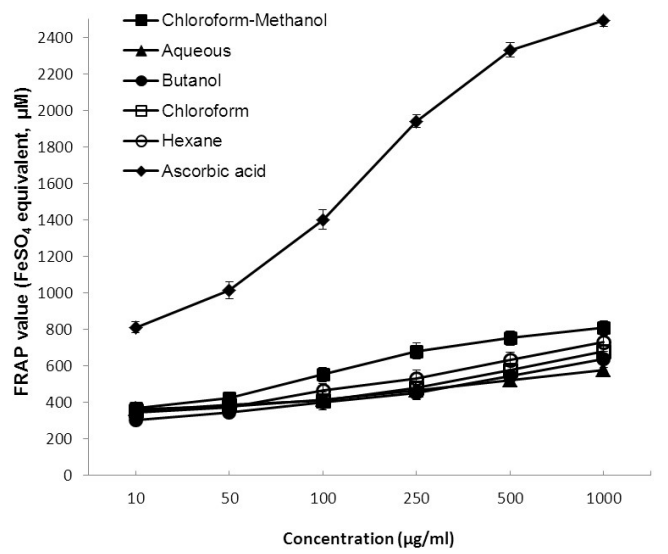

Figure 1. FRAP values of various extracts obtained from seeds of $A$. ampeloprasum subsp. persicum $(25-1000 \mu \mathrm{g} / \mathrm{mL})$ determined as ferrous sulfate equivalents. Values are means \pm SEM from three independent experiments.

\section{Discussion}

Allium ampeloprasum L. is an Allium species with wide traditional and dietary uses. Despite the potentially valuable medicinal and nutritional profile of this species, there was no research regarding antioxidant activity of various polarity extracts of leaves and seeds of $A$. ampeloprasum subsp. persicum. In the present study, total phenolic contents varied from 2.46 to $8.12 \mathrm{mg} \mathrm{GAE} / \mathrm{g}$ for various extracts of $A$. ampeloprasum subsp. persicum, and there were higher levels in the leaves extract than that of the seeds. Our data are in agreement with the values

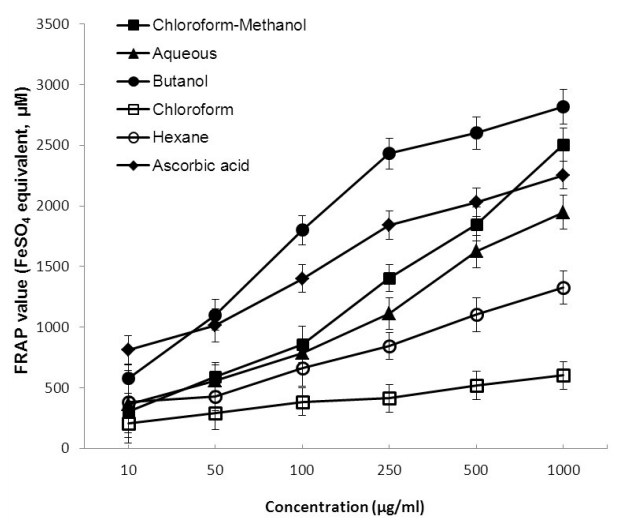

Figure 2. FRAP values of various extracts obtained from leaves of $A$. ampeloprasum subsp. persicum $(25-1000 \mu \mathrm{g} / \mathrm{mL})$ determined as ferrous sulfate equivalents. Values are means + SEM from three independent experiments.

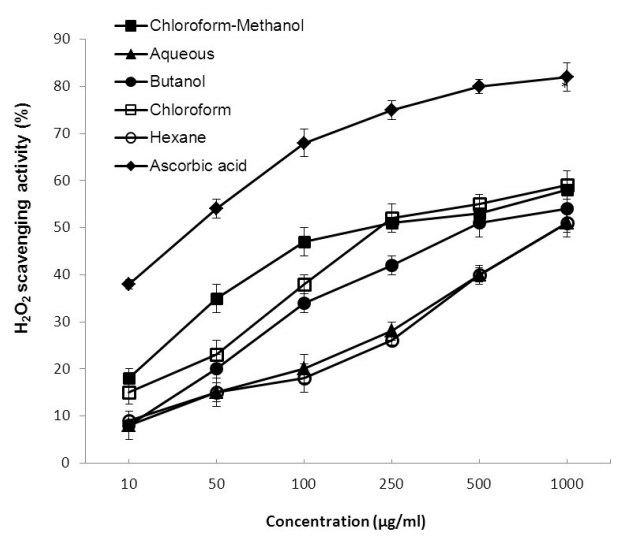

Figure 3. $\mathrm{H} 2 \mathrm{O} 2$ scavenging activity of various extracts obtained from seeds of $A$. ampeloprasum subsp. persicum $(25-1000 \mu \mathrm{g} / \mathrm{mL})$ tested by FOX1 Method. Values are means + SEM from three independent experiments. 


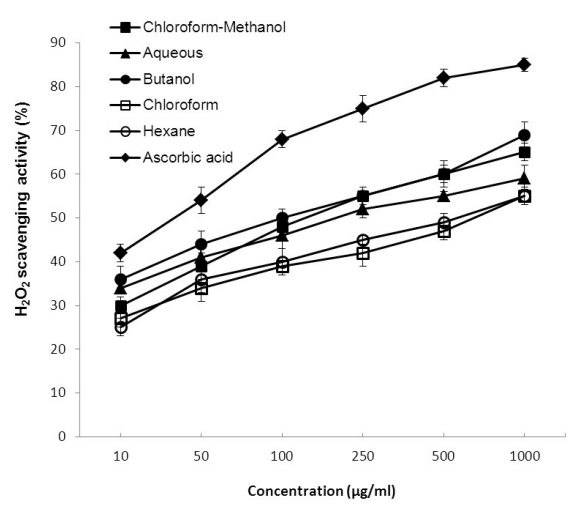

Figure 4. $\mathrm{H} 2 \mathrm{O} 2$ scavenging activity of various extracts obtained from leaves of $A$. ampeloprasum subsp. persicum $(25-1000 \mu \mathrm{g} / \mathrm{mL})$ tested by FOX1 method. Values are means + SEM from three independent experiments.

reported by some researchers (12). However, our results showed moderately low amount of phenolic compounds in different extracts of seeds and leaves of A. ampeloprasum subsp. persicum.

In the DPPH assay, the higher antioxidant activity is reflected in the lower $\mathrm{IC}_{50}$ value. It has been proposed that samples with $\mathrm{IC}_{50}$ lower than $50 \mu \mathrm{g} / \mathrm{mL}$ are very strong antioxidants, with $50-100 \mu \mathrm{g} / \mathrm{mL}$ are strong, with $101-150$ $\mu \mathrm{g} / \mathrm{mL}$ are moderate, and with $\mathrm{IC}_{50}$ greater than $150 \mu \mathrm{g} /$ $\mathrm{mL}$ are weak antioxidants (9). Butanol leave extract which contains more phenolic compounds such as flavonoids showed the lowest $\mathrm{IC}_{50}$ of DPPH scavenging $(315 \mu \mathrm{g} / \mathrm{mL})$. However, all extracts exhibited weak antioxidant activity. Similar to our results, Karamian and Hosseini reported the $\mathrm{IC}_{50}$ of DPPH $470 \mu \mathrm{g} / \mathrm{mL}$ for methanol leaves extract of $A$. ampeloprasum (13). Weak DPPH scavenging activity has also been reported for seeds of other Allium species including $A$. cepa (14).

Our results showed weak total antioxidant capacity for all seeds extract compared to ascorbic acid. However, chloroform-methanol extract which was rich in both polar and nonpolar compounds and the hexane extract containing nonpolar compounds exhibited more FRAP value. Several mono- and polyunsaturated fatty acids including linoleic, oleic and palmitic acid and also some phytosterols with antioxidant activities have been identified in seeds of Allium species (15). Phytosterols possess antioxidant property through radical scavenging and stabilizing the membranes $(16,17)$.

Unlike seeds extract, leaves extracts showed good total antioxidant capacity comparable to that of standard in a dose-dependent manner. Butanol extract exhibited the highest FRAP value that may be due to the relatively high contents of tannins, flavonoids and saponins.

Regarding $\mathrm{H}_{2} \mathrm{O}_{2}$ scavenging activity, butanol leave extract showed the less $\mathrm{IC}_{50}$ value indicating its strong antioxidant capacity. Chloroform-methanol extract also indicated moderate antioxidant capacity.

Various antioxidant activities have been reported for Allium species that may be attributed to different phytochemicals constituents including water-and lipidsoluble organosulfur compounds microelements, dietary fibers, saponins, polyphenols and flavonoids (18). Several known and new saponins such as spirostane and cholestane saponins have been isolated from A. ampeloprasum subsp. persicum (6). Important biological effects including effective antioxidant activities have also been established for natural saponins in various investigations (19).

\section{Conclusion}

In conclusion, our results showed moderately low amount of phenolic compounds and weak DPPH scavenging activity for all extracts of $A$. ampeloprasum subsp. persicum. However, leaves extracts showed good total antioxidant capacity and $\mathrm{H}_{2} \mathrm{O}_{2}$ scavenging activity. The best antioxidant activity was also found for butanol leave extract which may be attributed to high contents of tannins, flavonoids and saponins in this extract.

\section{Authors' contributions}

LS and BZ contributed to the idea and design of the study. The experimental procedures were done by SFN under the supervision of LS and BZ. The manuscript was prepared and written by LS and approved by all authors.

\section{Conflict of interests}

The authors declare no conflicts of interest. The authors alone are responsible for the content of the paper.

\section{Ethical considerations}

All procedures were approved by the ethics committee of Isfahan University of Medical Sciences (IR.MUI. REC.1395.1.072) and the authors observed ethical issues in accordance with the guidelines of National Committee of Ethics for Biomedical Researches.

\section{Funding/Support}

This study was financially supported by a research project No. 195072 from Isfahan University of Medical Sciences, Isfahan, Iran.

\section{References}

1. Anderson FA Jr, Spencer FA. Risk factors for venous thromboembolism. Circulation. 2003;107(23 Suppl 1):1916. doi: 10.1161/01.cir.0000078469.07362.e6.

2. Houston MC. The role of nutrition, nutraceuticals, vitamins, antioxidants, and minerals in the prevention and treatment of hypertension. Altern Ther Health Med. 2013;19 Suppl 1:32-49.

3. Yegdaneh A, Ghannadi A, Dayani L. Chemical constituents and biological activities of two Iranian Cystoseira species. Res Pharm Sci. 2016;11(4):311-7. doi: 10.4103/17355362.189307.

4. Mesripour A, Rafieian-Kopaei M, Bahrami B. The effects of Anethum graveolens essence on scopolamineinduced memory impairment in mice. Res Pharm Sci. 2016;11(2):145-51. 
5. Rahman K, Lowe GM. Garlic and cardiovascular disease: a critical review. J Nutr. 2006;136(3 Suppl):736s-40s. doi: 10.1093/jn/136.3.736S.

6. Sadeghi M, Zolfaghari B, Senatore M, Lanzotti V. Spirostane, furostane and cholestane saponins from Persian leek with antifungal activity. Food Chem. 2013;141(2):1512-21. doi: 10.1016/j.foodchem.2013.04.009.

7. Mousavi A, Kashi A, Davoodi D, Sanei Shariatpanahi M. Characterization of an Allium cultivated in Iran: the Persian leek. Belg J Bot. 2006;139(1):115-23.

8. Everette JD, Bryant QM, Green AM, Abbey YA, Wangila GW, Walker RB. Thorough study of reactivity of various compound classes toward the Folin-Ciocalteu reagent. J Agric Food Chem. 2010;58(14):8139-44. doi: 10.1021/ jf1005935.

9. Fidrianny I, Anggraeni NAS, Insanu M. Antioxidant properties of peels extracts from three varieties of banana (Musa sp.) grown in West Java-Indonesia. Int Food Res J. 2018;25(1):57-64.

10. Benzie IF, Strain JJ. The ferric reducing ability of plasma (FRAP) as a measure of "antioxidant power": the FRAP assay. Anal Biochem. 1996;239(1):70-6. doi: 10.1006/ abio.1996.0292.

11. Wolff SP. Ferrous ion oxidation in presence of ferric ion indicator xylenol orange for measurement of hydroperoxides. Methods Enzymol. 1994;233:182-9. doi: 10.1016/S0076-6879(94)33021-2.

12. Gorinstein S, Park YS, Heo BG, Namiesnik J, Leontowicz $\mathrm{H}$, Leontowicz $\mathrm{M}$, et al. A comparative study of phenolic compounds and antioxidant and antiproliferative activities in frequently consumed raw vegetables. Eur Food Res Technol. 2009;228(6):903-11. doi: 10.1007/s00217-0081003-y.
13. Karamian R, Hosseini DA. Screening of total phenol and flavonoid contents, antioxidant and antibacterial activities of the methanolic extract of Allium ampeloprasum L.(Alliaceae) from Iran. Journal of Science (Kharazmi University). 2014;14(3):225-38.

14. Yalcin H, Kavuncuoglu H. Physical, chemical and bioactive properties of onion (Allium cepa L.) seed and seed oil. J Appl Bot Food Qual. 2014;87:87-92. doi: 10.5073/ JABFQ.2014.087.013.

15. Golubkina NA, Nadezhkin SM, Agafonov AF, Kosheleva OV, Molchanova AV, Russo G, et al. Seed oil content, fatty acids composition and antioxidant properties as affected by genotype in Allium cepa L. and perennial onion species. Adv Hortic Sci. 2015;29(4):199-206. doi: 10.13128/ahs22738.

16. Yoshida Y, Niki E. Antioxidant effects of phytosterol and its components. J Nutr Sci Vitaminol (Tokyo). 2003;49(4):27780.

17. Mesripour A, Moghimi F, Rafieian-Kopaie M. The effect of Cinnamomum zeylanicum bark water extract on memory performance in alloxan-induced diabetic mice. Res Pharm Sci. 2016;11(4):318-23. doi: 10.4103/1735-5362.189308.

18. Benkeblia N. Free-radical scavenging capacity and antioxidant properties of some selected onions (Allium cepa L.) and garlic (Allium sativum L.) extracts. Braz Arch Biol Technol. 2005;48(5):753-9. doi: 10.1590/S151689132005000600011.

19. Ashraf MF, Abd Aziz M, Stanslas J, Ismail I, Abdul Kadir M. Assessment of antioxidant and cytotoxicity activities of saponin and crude extracts of Chlorophytum borivilianum. ScientificWorldJournal. 2013;2013:216894. doi: $\quad 10.1155 / 2013 / 216894$. 